\title{
Ueber die Einwirkung von Chloralhydrat auf Rhodanammonium;
}

von

Mr. Nencki und F. Schaffer.

Vor Kurzem erhielt einer von uns durch Erwärmen wässriger Lösungen von Chloressigsäure und Rhodanammonium eine schön krystallisirende Säure von der Zusammensetzung: $\mathrm{C}_{3} \mathrm{H}_{3} \mathrm{NS}_{2} \mathrm{O}$, welche mit dem Namen Rhodaninsäure ${ }^{1}$ ) bezeichnet wurde. Der Umstand, dass Rhodaninsäure, mit schwach oxydirenden Agentien behandelt, Farbstoffe lieferte, veranlasste uns, das Verhalten anderer organischer Chlorverbindungen gegen Sulfocyansäure und ihre Salze zu untersuchen. In Folgendem wollen wir über das Verhalten von Chloralhydrat gegen Rhodanammonium und eine dabei entstehende neue Verbindung berichten.

Wird Chloralhydrat in einem Kolben bis zur völligen Verflüssigung erwärmt und sodann mit der äquivalenten Menge trocknen und gepulverten Rhodanammoniums versetzt, so löst sich das letztere zum grossen Theil im Chloral auf, die Flüssigkeit färbt sich braun und neben dem Chloralgeruch wird auch der nach Sulfocyansäure bemerkbar. Es ist zweckmässig, jetzt den Kolben vom Sandbade zu entfernen und bei Zimmertemperatur sich die Reaction vollenden zu lassen. Versetzt man dann die erkaltete Masse mit viel Wasser, so entsteht ein starker Niederschlag, der auf dem Filter gesammelt und in heissem 90 proc. Alkohol gelöst wird. Beim Erkalten der heiss filtrirten alkoholischen Lösung krystallisirt die neue Substanz in langen, glänzenden Nadeln, die, anfangs gelb gefärbt, durch wiederholtes Umkrystallisiren aus heissem Alkohol schneeweiss erhalten werden. In den alkoholi-

1) Dies. Journ. [2] 16, 1 . 
schen Mutterlaugen bleibt noch ziemlich viel von dieser Substanz gelöst, jedoch vermengt mit einer anderen braunen, harzigen Materie, welche letztere in um so grösserer Menge entsteht, je länger Chloralhydrat mit Rhodanammonium erwärmt wurde. Die Analysen der in weissen Nadeln auskrystallisirten und über $\mathrm{SO}_{4} \mathrm{H}_{2}$ getrockneten Substanz ergaben Zahlen, aus welchen sich die empirische Formel: $\mathrm{C}_{5} \mathrm{H}_{5} \mathrm{Cl}_{6} \mathrm{~N}_{3} \mathrm{~S}$ berechnet.

$0,3869 \mathrm{Grm}$. der mit chromsaurem Blei verbrannten Substanz lieferten $0,2389 \mathrm{Grm} . \mathrm{CO}_{2}$ und $0,0703 \mathrm{Grm} . \mathrm{H}_{2} \mathrm{O}$ oder $16,84 \% \mathrm{C}$ und $2,02 \% \mathrm{H}$.

$0,4601 \mathrm{Grm}$. der Substanz gaben $49,5 \mathrm{Cem} . \mathrm{N}$ bei $13^{\circ}$ und $706 \mathrm{Mm}$. Barom. oder 11,79\% N, ferner 0,2865 Grm. gaben $31,5 \mathrm{Ccm}$. N-Gas bei $14^{0}$ und $709 \mathrm{Mm}$. Barom. oder $12,05 \% \mathrm{~N}$.

0,3278 Grm. Substanz mit Salpetersäure und salpetersaurem Silber im zugeschmolzenen Rohre, bis kein Druck mehr vorhanden, erhitzt, gaben $0,8662 \mathrm{Grm}$. $\mathrm{Ag} \mathrm{Cl}$ oder $60,61 \% \mathrm{Cl}$. Das Filtrat von $\mathrm{Ag} \mathrm{Cl}$ sammt Waschwasser mit salpetersaurem Barium gefällt gaben 0,2169 Grm. $\mathrm{Ba} \mathrm{SO}_{4}$ oder $9,08 \% \mathrm{~S}$.

0,2302 Grm. der Substanz gaben 0,5651 Grm. Ag Cl oder $60,59 \% \mathrm{Cl}$.

\begin{tabular}{|c|c|c|c|c|}
\hline \multicolumn{3}{|c|}{ Versuch. } & \multicolumn{2}{|c|}{ Theorie. } \\
\hline $\mathrm{C}$ & $16,84 \%$ & & $\mathrm{C}_{5}$ & $17,05 \% \mathrm{C}$ \\
\hline $\mathrm{H}$ & 2,02, & & $\mathrm{H}_{5}$ & $1,42, \mathrm{H}$ \\
\hline $\mathrm{N}$ & $11,79 "$ & und 12,05 & $\mathbf{N}_{3}$ & 11,92, \\
\hline $\mathrm{Cl}$ & 60,61 " & und 60,59 & $\mathrm{Cl}_{6}$ & $60,51 "$ \\
\hline $\mathbf{S}$ & 2,08, & & $\mathbf{s}$ & $9,09 "$ \\
\hline
\end{tabular}

Der Körper $\mathrm{C}_{5} \mathrm{H}_{5} \mathrm{~N}_{3} \mathrm{Cl}_{6} \mathrm{~S}$ ist in Wasser unlöslich, nur wenig löslich in kaltem Alkohol und Aether; ziemlich leicht dagegen in heissem Alkohol. In wässrigen Mineralsäuren und Alkalien ist er ebenfalls unlöslich. Concentrirte Schwefelsäure löst ihn bei gelindem Erwärmen auf, wobei aber Chloral entweicht. In der Lösung bleibt Ammoniak an Schwefelsäure gebunden. Auch durch Erwärmen mit Kali- oder Natronlauge wird diese Substanz, jedoch unter völliger Zersetzung, gelöst. Trocken erhitzt schmilzt er nicht, sondern zersetzt sich unverkohlt etwa bei $180^{\circ}$. Durch Metalloxyde, Jod und andere Entschwefelungsagentien lässt sich diesem Körper der Schwefel nicht ent- 
ziehen, ein Zeichen, dass das Schwefelatom darin nicht mit beiden Valenzen an Kohlenstoff gebunden ist. Die Entstehung dieser Substanz aus Chloralhydrat und Rhodanammonium veranschaulicht folgende Gleichung:

$\left(\mathrm{CCl}_{3}-\mathrm{CH}(\mathrm{OH})_{2}\right)_{2}+(\mathrm{CN} \mathrm{SN} \mathrm{H})_{4}=\mathrm{C}_{5} \mathrm{H}_{5} \mathrm{Cl}_{6} \mathrm{~N}_{3} \mathrm{~S}+\mathrm{CNSH}+4 \mathrm{H}_{2} \mathrm{O}$ und man könnte sie auffassen als eine molekulare Verbindung von Sulfocyansäure mit zwei Molekülen des bis jetzt unbekannten Trichloräthylidenimids : $\mathrm{CCl}_{3} \mathrm{CH}-\mathrm{NH}$.

$$
\left(\mathrm{CCl}_{3}-\mathrm{CHNH}\right)_{2} \mathrm{CNSH}=\mathrm{C}_{5} \mathrm{H}_{5} \mathrm{Cl}_{6} \mathrm{~N}_{3} \mathrm{~S} \text {. }
$$

Dass der von uns erhaltene Körper aber nicht einfach ein sulfocyansaures Salz ist, geht schon daraus hervor, dass eine alkoholische Lösung mit Eisenchlorid nicht die für Rhodansalze so charalkteristische rothe Färbung giebt. Es gelang uns auch nicht, auf anderem Wege daraus das Trichloräthylidenimid zu isoliren.

Bern, im November 1878.

\section{Die chemische Synthese,}

ein chemischer Traum;

beleuchtet von

H. $\mathrm{K} \circ \mathrm{l} \mathrm{b}$ e.

Es hat sich unlängst ereignet, dass ein deutscher Chemiker einen Traum hatte, denselben niederschrieb und diese Niederschrift zur Festrede benutzte, welche am 25. Juli d. J. zur Vorfeier des Geburts- und Namensfestes des Königs Ludwig von Bayern in der öffentlichen Sitzung der Königl. Akademie der Wissenschaften zu München von ihm gehalten und hernach durch den Druck veröffentlicht ist.

Diese von chemischer Synthese ausgehende Rede hat vor andern Träumen Nichts voraus; sie ist reich an barocken Ideen, unlogischen Entwickelungen, kühnen Gedankensprïngen, so wie an Trivialitäten und nicht zur 